\title{
Ocorrência do molusco asiático Corbicula fluminea (Müller, 1774) (Bivalvia, Corbiculidae) no baixo rio Negro, Amazônia central
}

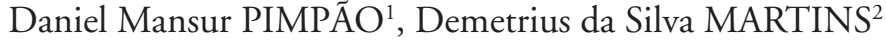

\section{RESUMO}

O rio Negro é um dos maiores afluentes do rio Amazonas, mas poucos moluscos foram registrados até o momento para aquele rio, representados apenas por gastrópodes. Foi registrada a presença do molusco bivalve exótico Corbicula fluminea na margem esquerda do baixo rio Negro, no lago do Tupé e no Catalão - margem direita do rio Negro, todas localidades no município de Manaus, Brasil. O registro foi realizado por meio da coleta de conchas e espécimes vivos. É o primeiro registro de $C$. fluminea para o estado do Amazonas e Amazônia central.

PalaVRaS-CHAVE: Corbicula fluminea, espécie exótica, Tupé, Amazônia, América do Sul.

\section{Occurrence of the Asian mollusc Corbicula fluminea (Müller, 1774) (Bivalvia, Corbiculidae) in the lower Rio Negro, Central Amazon Region, Brazil}

\section{ABSTRACT}

The Rio Negro is one of the biggest Rio Amazonas tributaries. Few molluscs have been registered to that river yet, represented only by gastropods. It is reported the occurrence of the exotic bivalve mollusc Corbicula fluminea in left bank margin of Rio Negro, Lago do Tupé and Catalão - right bank margin of Rio Negro, all localities in the municipality of Manaus, Brazil. The species is recorded by a collection of shells and specimens alive. This is the first occurrence of $C$. fluminea in the Amazon State and Central Amazon.

KEY-WORDS: Corbicula fluminea, exotic species, Tupé, Amazon, South America.

1 Instituto Nacional de Pesquisas da Amazônia (INPA), Av. André Araújo, 2936, Caixa Postal 478, 69011-970, Manaus, AM, Brasil. Bolsista PCI/MCT 380193/2004-3. e- mail: danielpimpao@yahoo.com.br

${ }^{2}$ Laboratório de Malacologia, Instituto de Biociências, UFRGS, Av. Bento Gonçalves, 9500 prédio 43435, 201 CEP: 91501-970.

e-mail: demetriusmartins@yahoo.com.br 
O rio Negro é um dos maiores afluentes do rio Amazonas e se caracteriza, segundo Goulding et al. (1988) por suas águas pretas, ser extremamente pobre em sais minerais e $\mathrm{pH}$ entre 3,6 a 5,8. O lago do Tupé está localizado na margem esquerda do rio Negro, à montante da cidade de Manaus. O lago apresenta características típicas de águas pretas (Darwich et al., 2005). A localidade conhecida por Catalão fica no encontro dos rios Negro e Solimões, em frente à cidade de Manaus. Esta região é banhada pelas águas dos dois rios, com intensidade variável ao longo do ano.

Os moluscos de água doce não são comumente vistos no rio Negro (Sioli, 1984) e em ambientes de águas pretas da Amazônia. Irmler (1975) cita apenas duas espécies de gastrópodes para a floresta de inundação do rio Tarumã Mirim, área próxima à Manaus, Gundlachia bakeri Pilsbry, 1913 e Ampularius papyraceus [=Pomacea papyracea (Spix, 1827)].

No presente trabalho é feito o primeiro registro de Corbicula fluminea no estado do Amazonas, Brasil, uma das espécies que, segundo Mansur et al. (1999), são de origem asiática e invasoras de ambientes límnicos no Brasil.

\section{Corbicula fluminea (Müller, 1774) Figura 1}

Material examinado: Brasil, Amazonas, Manaus, lago do Tupé, 0301'25,2”S 60¹5'58,6”W, 23.i.2005, D.M. Pimpão col., 1 concha (INPA 536); praia do Tupé, 0302'15,2”S $60^{\circ} 15^{\prime} 14,8^{\prime \prime W}$, 11.ix.2005, D.M. Pimpão \& M.S. Rocha col., 2 conchas (INPA 882); praia do Tupé, 0302'22,3”S 60¹4'17,2”W, 11.ix.2005, D.M. Pimpão \& M.S. Rocha col., 1 concha (INPA 881); praia do Tupé, $03^{\circ} 02^{\prime} 24,2^{\prime \prime} S$ $60^{\circ} 14^{\prime} 31,2^{\prime \prime W}, 18 . x i i .2004$, D.M. Pimpão \& D.C. Fettuccia col., 22 conchas (INPA 512); praia do Tupé, $03^{\circ} 02^{\prime 2} 24,2^{\prime \prime S}$ 6014’31,2”W, 22.i.2005, D.M. Pimpão \& E.N. dos Santos Silva col., 31 conchas (INPA 535);praia do Tupé, 0302'24,2"S 60¹4'31,2”W, 26.ii.2005, D.M. Pimpão col., 3 conchas (INPA 623); Iranduba, Catalão, margem direita do rio Negro, 030.'58"S 5955'11"W, 07.x.2006, D.M. Pimpão \& M.S. Rocha col., 1 exemplar e 11 conchas (INPA 1120).

Ao longo do ano foram feitas amostragens qualitativas no lago do Tupé e na margem esquerda do rio Negro, próxima ao lago. A amostragem das áreas submersas foi feita manualmente ou com auxílio de uma rede de mão (puça ou rapiché), no fundo arenoso do rio Negro e no fundo arenoso com folhiço do lago. As áreas emersas como praia arenosa, no rio, e igapó, no lago, foram amostradas por meio de visualização direta de conchas. Um incursão foi feita à margem direita do rio Negro, Catalão, durante o final do período de vazante e seca, em outubro de 2006. Os exemplares foram coletados manualmente, junto à margem. A identificação da espécie foi feita a partir da comparação com material depositado na coleção do INPA e identificado pela Dra. M.C.D. Mansur e com base em Martins et al. (2004). O material coletado foi depositado na Coleção de Moluscos do INPA.

Caracterização das conchas: valvas espessas, com sulcos concêntricos bastante evidentes e espaçados; perióstraco brilhoso em alguns exemplares, de coloração marrom escura a preta, liso; formato triangular rostrado posteriormente nos maiores espécimes e mais eqüilateral nos menores; eqüivalve; umbo alto, arredondado, inflado; superfície interna das valvas esbranquiçada; linha palial e impressão dos músculos adutores evidentes, sem seio palial. Charneira com três dentes cardinais em cada valva e dentes laterais alongados e serrilhados: valva esquerda com um dente lateral anterior e outro posterior e valva direita com dois dentes laterais de posição anterior e posterior.

Comentário: um total de 71 conchas de Corbicula fluminea e um espécime vivo foram coletados: 59 na praia do Tupé, margem esquerda do rio Negro; uma concha encontrada em um igapó em uma margem do lago do Tupé distante do canal, que faz conexão com o rio; e 11 conchas e um espécime vivo no Catalão, margem direita do rio Negro.

Ambientes de águas pretas na Amazônia, conforme a caracterização de Sioli (1984), não apresentam parâmetros abióticos favoráveis a muitos moluscos. O registro de somente conchas no lago e margem esquerda do rio Negro à montante de Manaus e do encontro com o rio Solimões, deixa dúvidas sobre a existência da espécie nestes dois locais. A corroboração da ocorrência da espécie e não de um transporte pós morte de conchas só poderá ser feito futuramente, quando da coleta de animais vivos. Cabe destacar que a maioria das conchas encontrava-se em bom estado de conservação, com o ligamento preservado. A concha obtida no lago apresentavase com as valvas unidas, porém com a região central gasta de ambas as valvas.

Entretanto, a ocorrência de Corbicula fluminea no Catalão, margem direita do rio Negro, e no estado do Amazonas foi confirmada pela coleta de um espécime vivo e 11 conchas. Devido à influência de águas barrentas do rio Solimões na área do Catalão, a resistência do bivalve invasor em ambientes típicos de águas pretas não pode ser avaliada. Novas coletas no local deverão ser realizadas, em busca de mais exemplares de C. fuminea.

Registros da espécie já haviam sido feitos para áreas circundantes, como o baixo rio Amazonas no estado do Pará (Beasley et al., 2003), na Venezuela (Martínez, 1987), na divisa entre Peru e Colômbia (Ramírez et al., 2003). Deste modo, a expansão na distribuição conhecida da espécie já poderia ser esperada. 

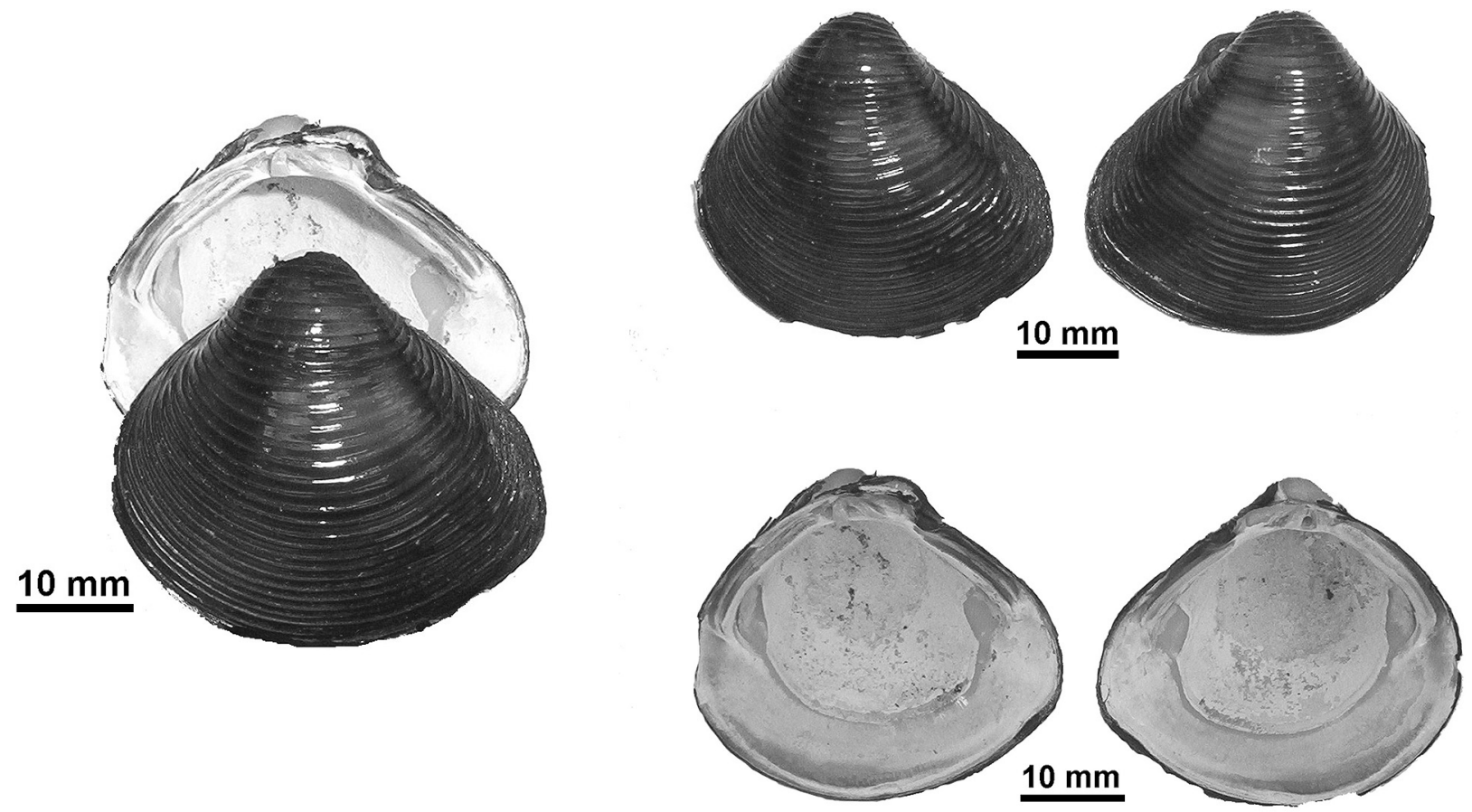

Figura 1 - Conchas de Corbicula fluminea (Müller, 1774) em diferentes vistas, coletadas na praia do Tupé, Manaus, AM, Brasil; Iote INPA 881.

De qualquer modo, o registro de Corbicula fluminea para o Amazonas amplia consideravelmente a distribuição conhecida dessa espécie invasora na América do Sul e no Brasil.

\section{AGRADECIMENTOS}

Aos coordenadores - Edinaldo N. dos Santos Silva e Veridiana V. Scudeller - e participantes do Biotupé, pela possibilidade de participar do projeto e pelo auxílio em campo; à Fapeam e Programa de Capacitação em Taxonomia (MCT/ CNPq/Capes) pelos auxílios fornecidos; aos mestrandos Daniela Fettuccia e Marcelo Rocha, pelo auxílio nas coletas; a Maria Cristina D. Mansur e a Célio Magalhães, pelas sugestōes e críticas ao trabalho.

\section{BIBLIOGRAFIA CITADA}

Beasley, C.R.; Tagliaro, C.H.; Figueiredo, W.B. 2003. The occurrence of the Asian clam Corbicula fluminea in the Lower Amazon Basin. Acta Amazonica, 33(2): 317-324.

Darwich, A.J.; Aprile, F.M.; Robertson, B.A. 2005. Variáveis limnológicas: contribuição ao estudo espaço-temporal de águas pretas amazônicas. In: Santos-Silva, E.N.; Aprile, F.M.; Scudeller, V.V.; Melo, S. (Orgs). Biotupé: Meio físico, diversidade biológica e sociocultural do Baixo rio Negro, Amazônia Central. Manaus, AM. Editora do INPA. p. 19-33.

Goulding, M.; Leal Carvalho, M.; Ferreira, E.G. 1988. Rio Negro: rich life in poor water: Amazonian diversity and foodchain ecology as seen through fish communities. SPB Academic Publishing, The Hague. 200pp.

Irmler, U. 1975. Ecological studies of the aquatic soil invertebrates in three inundation forests of Central Amazonia. Amazoniana, 5(3): 337-409.

Mansur, M.C.D.; Richinitti, L.M.Z.; Santos, C.P. 1999. Limnoperna fortunei (Dunker, 1857), molusco bivalve invasor, na Bacia do rio Guaíba, Rio Grande do Sul, Brasil. Biociências, 7(2): 147-150.

Martínez, R.E. 1987. Corbicula manilensis molusco introducido em Venezoela. Acta Cient. Venez., 38: 384-385.

Martins, D.S.; Veitenheimer-Mendes, I.L.; Faccioni-Heuser, M.C. 2004. Corbicula (Bivalvia, Corbiculidae) em simpatria no lago Guaíba, Rio Grande do Sul, Brasil. Biociências, 12(2): 129138.

Ramírez, M.; Paredes, C; Arenas, J. 2003. Moluscos del Peru. Rev. Biol. Trop., 51(3): 225-284

Sioli, H. 1984. The Amazon and its main affluents: Hydrography, morphology of the river courses, and river types. In: Sioli, H. The Amazon: limnology and landscape ecology of a mighty tropical river and its basin. Dr.W.Junk Publishers, Dordrecht. 763pp.

Recebido em 06/10/2006

Aceito em 03/09/2008 
